
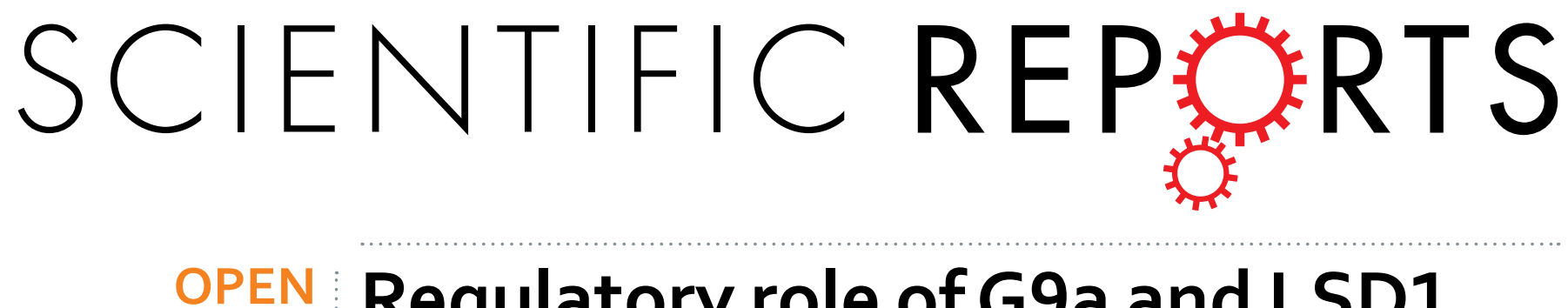

\title{
Regulatory role of G9a and LSD1 in the Transcription of Olfactory Receptors during Leukaemia Cell Differentiation
}

Accepted: 10 March 2017

Published: 07 April 2017

\author{
Hyeonsoo Jung ${ }^{1}$, Yun-Cheol Chae ${ }^{1}$, Ji-Young Kim ${ }^{1}$, Oh-Seok Jeong ${ }^{1}$, Hoon Kook ${ }^{2}$ \& \\ Sang-Beom Seo
}

Recent studies have reported the ectopic expression of olfactory receptors (ORs) in non-olfactory tissues, however, their physiological roles were not well elucidated. ORs are expressed in and function in different types of cancers. Here, we identified that the $\mathrm{H} 3 \mathrm{~K} 9 \mathrm{me} 2$ levels of several $O R$ promoters decreased during differentiation in the HL-60, human myeloid leukaemia cell line, by all-trans-retinoic acid (ATRA). We found that the differential OR promoters $\mathrm{H} 3 \mathrm{~K} 9 \mathrm{me} 2$ levels were regulated by $\mathrm{G} 9 \mathrm{a}$ and LSD1, resulting in the decrease of $O R$ s transcription during HL-60 differentiation. G9a and LSD1 could regulate the expression of $O R s$ in several non-olfactory cells via the methylation and demethylation of $\mathrm{H} 3 \mathrm{~K} 9 \mathrm{me} 2$. In addition, we demonstrated that knockdown of $O R$ significantly reduced cell proliferation. Therefore, the epigenetic regulation of $O R$ s transcription is critical for carcinogenesis.

G9a is a histone methyltransferase (HMTase), belonging to the Su(var)3-9 family of proteins, and it catalyses histone $\mathrm{H} 3 \mathrm{~K} 9$ mono- and di-methylation associated with transcriptional repression ${ }^{1}$. Transcriptional regulation by G9a and its homologous HMTase G9a-like protein (GLP), is involved in many cellular processes. For example, G9a (or GLP) is critical for early embryo development and embryonic stem cell differentiation in the mouse ${ }^{2}$. G9a knockout mice marked with dramatically reduced H3K9 methylation, exhibited severe growth defects in early development ${ }^{2,3}$. G9a also attenuates DNA methylation levels through the suppression of ubiquitin-like with PHD and ring finger domains 1 (UHRF1) which plays an essential function to maintain DNA methylation during HL-60 differentiation ${ }^{4-6}$. In HL-60 cells, G9a represses Janus kinase 2 (JAK2), the catalyst of H3Y41 phosphorylation, resulting in the inhibition of JAK2-H3Y41P-HP1 $\alpha$ pathway-mediated leukaemogenesis ${ }^{7,8}$. FAD-dependent amine oxidase, lysine-specific demethylase 1 A (LSD1) is a unique protein with the ability to catalyse the demethylation of $\mathrm{H} 3 \mathrm{~K} 4 \mathrm{me} 2$ and $\mathrm{H} 3 \mathrm{~K} 9 \mathrm{me} 2$, and therefore act as a transcriptional repressor or activator, respectively ${ }^{9,10}$. LSD1 was first reported to demethylate $\mathrm{H} 3 \mathrm{~K} 4 \mathrm{me} 2$ and repress transcription with the CoREST complex. However, LSD1 also catalyses the demethylation of $\mathrm{H} 3 \mathrm{~K} 9 \mathrm{me} 2$ with the androgen or oestrogen receptor, and acts as a transcriptional activator ${ }^{9-11}$.

Olfactory receptors (ORs) are G protein-coupled receptors mainly expressed in the olfactory sensory neurons (OSNs) of the olfactory epithelium. ORs play roles in detecting odorants and guiding OSNs axons to the brain ${ }^{12,13}$. Mammals typically have $\sim 1,000$ OR genes organised in gene clusters on most chromosomes, but about 350 putative functional genes encode ORs in humans ${ }^{14}$. ORs are the largest gene superfamily in mammals, but each olfactory neuron expresses only a single OR allele, according to the "one receptor, one neuron" rule ${ }^{15}$. Recent studies have shown that the singular OR expression in mammals is mediated by the HMTase G9a and demethylase LSD $1^{16,17}$. Before a single OR gene is chosen, OR genes are marked with H3K9me2 by G9a which has a critical role in maintaining OR silencing in neurons ${ }^{17}$. Upon further differentiation, all OR genes in a neuron exhibit the hallmarks of constitutive heterochromatin, $\mathrm{H} 3 \mathrm{~K} 9 \mathrm{me} 3$ and $\mathrm{H} 4 \mathrm{~K} 20 \mathrm{me} 3$, and are completely silenced ${ }^{18}$. In developmental stage, LSD1 catalyses the demethylation of $\mathrm{H} 3 \mathrm{~K} 9 \mathrm{me} 2$ of a single OR allele, and that selected OR becomes activated while all other ORs remain repressed. The feedback driven by OR expression induces the unfolded

${ }^{1}$ Department of Life Science, College of Natural Sciences, Chung-Ang University, Seoul 156-756, Republic of Korea. ${ }^{2}$ Environmental Health Center for Childhood Leukaemia and Cancer, Department of Pediatrics, Chonnam National University Hwasun Hospital, Hwasun 519-809, Republic of Korea. Correspondence and requests for materials should be addressed to S.B.S. (email: sangbs@cau.ac.kr) 


\begin{tabular}{|c|c|c|c|c|c|c|}
\hline Gene name & $\begin{array}{l}\text { GenBank } \\
\text { Accession no. }\end{array}$ & Description & $\begin{array}{l}\text { H3K9-me2 } \\
\text { Enrichment }\end{array}$ & FDR & TSS (bp) & Distance (bp) \\
\hline OR7A17 & BC101587 & olfactory receptor, family 7 , subfamily A, member 17 & 0.6 & 0 & -14853264 & -831 \\
\hline OR1Q1 & NM_012364 & olfactory receptor, family 1 , subfamily $Q$, member 1 & 0.58 & 0.0197368 & 124416837 & -1622 \\
\hline OR4K15 & NM_001005486 & olfactory receptor, family 4 , subfamily K, member 15 & 0.56 & 0.0296053 & 19513517 & -267 \\
\hline OR4K1 & NM_001004063 & olfactory receptor, family 4 , subfamily $\mathrm{K}$, member 1 & 0.5 & 0.00701754 & 19473665 & 378 \\
\hline OR10G2 & NM_001005466 & olfactory receptor, family 10 , subfamily $G$, member 2 & 0.5 & 0.0601504 & -21172838 & -1032 \\
\hline OR5K4 & NM_001005517 & olfactory receptor, family 5 , subfamily $\mathrm{K}$, member 4 & 0.49 & 0.0802855 & 99555387 & 89 \\
\hline OR2A1 & NM_001005287 & olfactory receptor, family 2, subfamily $A$, member 1 & 0.49 & 0.0802855 & 143646150 & -971 \\
\hline OR4F6 & NM_001005326 & olfactory receptor, family 4 , subfamily $F$, member 6 & 0.48 & 0.00554017 & 100163445 & -1913 \\
\hline OR1N1 & NM_012363 & olfactory receptor, family 1 , subfamily $\mathrm{N}$, member 1 & 0.48 & 0.0802855 & -124329393 & -578 \\
\hline $\mathrm{OR} 1 \mathrm{OH} 4$ & NM_001004465 & olfactory receptor, family 10 , subfamily $\mathrm{H}$, member 4 & 0.48 & 0 & 15920817 & -269 \\
\hline
\end{tabular}

B

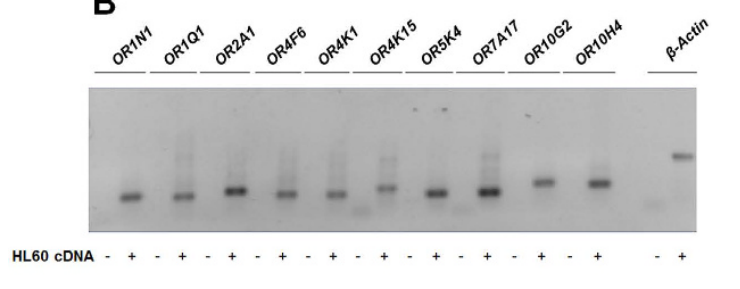

C
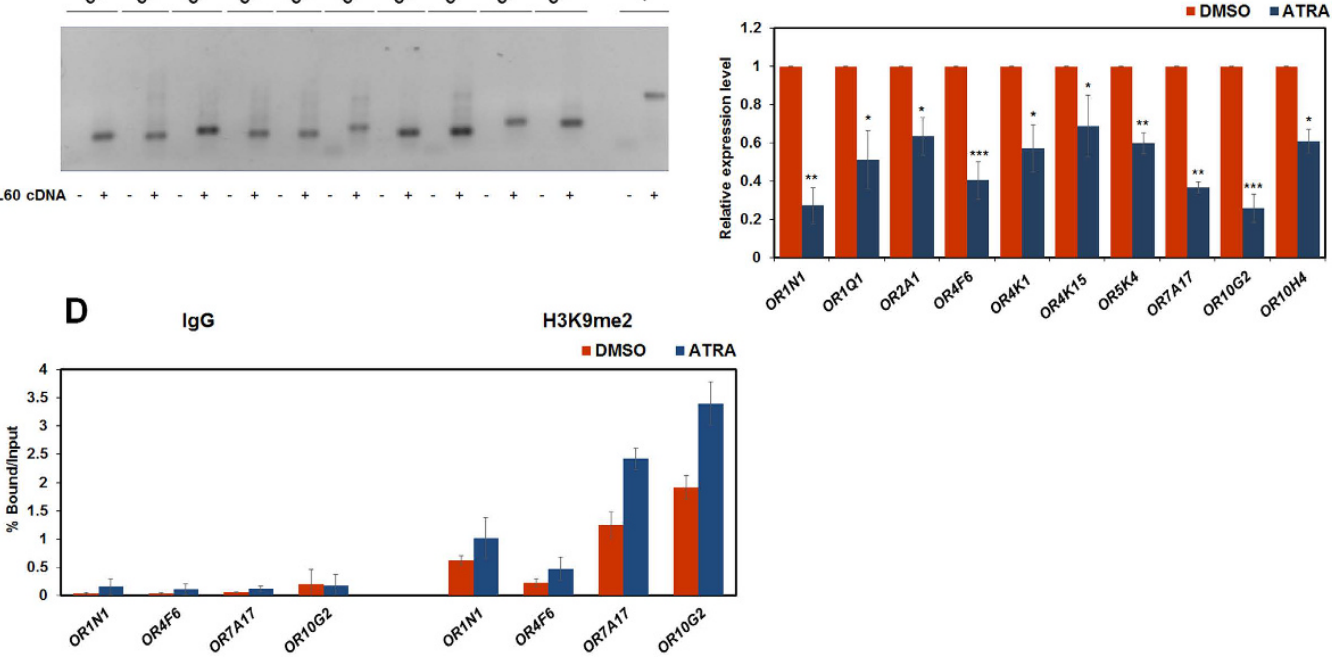

Figure 1. Expression of ORs is repressed during ATRA-induced HL-60 differentiation. HL-60 cells were treated with ATRA $(1 \mu \mathrm{M})$ or DMSO for $48 \mathrm{~h}$. (A) The H3K9me2 level of ORs during HL-60 differentiation was analysed from ChIP-chip analysis data of previous research ${ }^{29}$. (B) The expression of 10 ORs in HL-60 cells was confirmed by RT-PCR using primer pairs for qRT-PCR (Supplementary Table S1). $\beta$-actin was used as a positive control. Full-length gel is presented in Supplementary Figure S4. (C) The mRNA levels of each $O R$ were analysed using qRT-PCR. All results represent at least three independent experiments $( \pm \mathrm{SDs}) .{ }^{\star} P<0.05$, ${ }^{\star *} P<0.01,{ }^{* *} P<0.001$. (D) ChIP analyses were performed using anti-H3K9me2 antibodies, and results were confirmed by qRT-PCR. Recruitment of H3K9me2 to the OR1N1, OR4F6, OR7A17, and OR10G2 promoters was normalised by input.

protein response (UPR) and results in the expression of adenylyl cylase 3 (Adcy3), a negative regulator of LSD1 ${ }^{19}$. In this way, G9a and LSD1 can regulate single OSN to express and maintain the expression of only one OR ${ }^{20}$.

Recently, it was revealed that different ORs are expressed in non-olfactory tissues including tissues from the testis, tongue, heart, blood, prostate and brain, as well as in spermatozoa ${ }^{21-27}$. Ectopically expressed ORs have their own physiological functions. For example, hOR17-4 is expressed in testis and spermatozoa and has crucial roles in sperm chemotaxis ${ }^{22}$. OR10J5 is expressed in the heart and is involved in angiogenesis ${ }^{27}$. Additionally, overexpressed OR51E2 (PSGR, prostate-specific G-protein-coupled receptor) enhanced oncogenesis in prostate tissue through activation of NF- $\kappa B^{28}$. However, the physiological roles of ORs in these tissues are still not well understood.

Here, we identified a decrease in OR expressions during human myeloid leukaemia cell line, HL-60, differentiation by all-trans-retinoic acid (ATRA). We found that G9a was recruited to the OR promoters while the levels of LSD1 at $O R$ promoter were reduced, which caused repression of $O R$ gene expression. Knockdown of OR10G2 inhibited the cell proliferation, suggesting that expression of ORs might have regulatory roles in leukaemia cell maintenance.

\section{Results}

ORs are down-regulated during ATRA-mediated HL-60 differentiation. Previously, it was shown that the H3K9me2 level of OR51E1 promoter increased during ATRA-mediated differentiation of HL-60 cells ${ }^{29}$. Recently, the function of ORs in non-olfactory tissues has been investigated. It has been reported that the activation of ORs is important for the maintenance of blood progenitor cells in Drosophila ${ }^{25}$. Therefore, we hypothesised that differential H3K9me2 levels of ORs promoter may imply a regulatory role of ORs in leukaemic haematopoiesis. We analysed ChIP-chip data and found that H3K9me2 levels of other ORs were also increased 
upon ATRA treatment. (Fig. 1A). The differential expressions of the top 10 ORs in ChIP-chip data sets, as determined by changes in the $\mathrm{H} 3 \mathrm{~K} 9 \mathrm{me} 2$ level, was measured during HL-60 differentiation. First, we checked the expression of these ORs in HL-60 cells using RT-PCR (Fig. 1B). Next, HL-60 cells were treated with ATRA for $48 \mathrm{~h}$ and the mRNA expression levels of $O R$ s were analysed by qRT-PCR. The OR expression was down-regulated during the ATRA-mediated differentiation of HL-60 cells (Fig. 1C). We focused on OR1N1, OR4F6, OR7A17, and OR10G2, all of which showed significant decreases in transcription levels compared to the other OR genes analysed. We conducted ChIP-qPCR to confirm the promoter $\mathrm{H} 3 \mathrm{~K} 9$ methylation levels of these ORs from ChIPchip data. Consistently, H3K9me2 levels of OR promoters increased after $48 \mathrm{~h}$ of treatment of ATRA (Fig. 1D). Therefore, we concluded that the expression of ORs is repressed during ATRA-meditated differentiation in HL-60 cells through increased levels of promoter $\mathrm{H} 3 \mathrm{~K} 9 \mathrm{me} 2$.

G9a and LSD1 regulate expression of ORs in HL-60 cells. Epigenetic regulations of tumour suppressors, miRNAs, and transcription factors involved in the differentiation of leukaemic cells ${ }^{8,29-35}$. To further investigate the epigenetic regulation of ORs, we overexpressed several epigenetic modifiers that are well known to regulate $\mathrm{H} 3 \mathrm{~K} 9 \mathrm{me} 2$. H3K9me2 is added by G9a and Suv39h1, and removed by KDM3B ${ }^{1,29,36,37}$. We also tested LSD1, which functions as both a transcriptional activator and repressor by removing H3K4me2 and H3K9me2, respectively ${ }^{9,10}$. G9a repressed expression of OR1N1 and OR10G2 in HCT116 and H1299 cells in manners similar to those reported in olfactory neurons, while Suv39h1 had no effect (Fig. 2A). In addition, LSD1 activated OR1N1 and OR10G2 expression in HCT116 and H1299 cells, suggesting that LSD1 can function as a H3K9me2 demethylase in OR expression (Fig. 2A). However, KDM3B could not regulate the expression of ORs. The regulation of OR4F6 and OR7A17 by G9a and LSD1 were also detected in 293T cells (Supplementary Figure S1A). These data indicated that G9a and LSD1 could regulate ORs expression in olfactory neurons and other cell lines including HCT116, H1299 and 293T. Furthermore, the expression levels of OR1N1, OR4F6, OR7A17, and OR10G2 in HL-60 cells increased and decreased following shRNA knockdown of G9a and LSD1, respectively (Supplementary Figure S1B and C). Treatment with the G9a specific inhibitor, BIX01294, also resulted in increased expression of ORs (Fig. 2B and Supplementary Figure S1D). However, the GSK-LSD1, LSD1 specific inhibitor, repressed the expression of ORs (Fig. 2C and Supplementary Figure S1E). Taken together, these results suggest that G9a represses, and LSD1 activates OR expression in HL-60 cells. Moreover, MEF G9a knockout cells exhibited increased expression of the mouse orthologues of OR1N1 and OR10G2, Olfr351 and Olfr1510 compared to wild type cells (Supplementary Figure S1F). These data demonstrate that G9a and LSD1 play key regulatory roles in the expression of ORs in different cell lines.

We tested whether the regulatory roles of G9a and LSD1 affect the promoter activity of ORs using luciferase reporter assay. As expected, G9a could repress OR1N1 and OR10G2 promoter activities, while LSD1 activated them (Fig. 2D). Furthermore, consistent with previous data, BIX01294-mediated G9a inhibition resulted in activation of ORs promoter activities and GSK-LSD1 treatment led to repression of ORs promoter activities (Fig. 2E and F). We obtained the same results for OR4F6 and OR7A17 (Supplementary Figure S2A-C). These results suggest that G9a and LSD1 function as transcriptional regulators of ORs through affecting the promoter region.

The change in OR expression caused by G9a and LSD1 is mediated via the level of H3K9me2. During ATRA-mediated HL-60 differentiation, we showed that H3K9me2 levels on the promoters of each ORs increased (Fig. 1D). We further examined whether G9a or LSD1 regulate OR expression via the methylation or demethylation of $\mathrm{H} 3 \mathrm{~K} 9$ respectively, by ChIP-qPCR. The recruitment of G9a to OR promoters increased $48 \mathrm{~h}$ after ATRA treatment, while the amount of LSD1 at OR promoters decreased (Fig. 3A and Supplementary Figure 3A). Furthermore, H3K9me2 levels were increased at $O R$ promoters. However, during HL-60 differentiation, the level of H3K4me2 at OR1N1, OR4F6, OR7A17, and OR10G2 promoters decreased, consistent with the low ORs mRNA expression levels. To further confirm the roles of G9a and LSD1 in HL-60 differentiation, we treated HL-60 cells with BIX01294 and GSK-LSD1, respectively. Treatment with BIX01294 inhibited the recruitment of G9a to OR promoter regions and resulted in decreased H3K9me2 levels (Fig. 3B and Supplementary Figure 3B). In contrast, treatment with GSK-LSD1 resulted in decreased LSD1 recruitment to the $O R$ promoters and inhibited the demethylation of $\mathrm{H} 3 \mathrm{~K} 9 \mathrm{me} 2$ (Fig. 3C and Supplementary Figure 3C). Unexpectedly, GSK-LSD1 treatment also increased H3K4me2 level, suggesting that LSD1 might demethylate $\mathrm{H} 3 \mathrm{~K} 4 \mathrm{me} 2$ and $\mathrm{H} 3 \mathrm{~K} 9 \mathrm{me} 2$ on $\mathrm{OR}$ promoter regions. Taken together, these data suggest that G9a and LSD1 regulate H3K9 methylation levels during ATRA-mediated HL-60 differentiation.

Knockdown of OR10G2 inhibited the cell proliferation and induced HL-60 differentiation. Given the fact that the expression of ORs decreased during ATRA-mediated HL-60 differentiation, ORs may play important roles in leukaemia cell proliferation or differentiation. To analyse the function of ORs in HL-60 cells, we designed shRNAs targeting OR10G2 and generated stable OR10G2 knockdown HL-60 cells (Fig. 4A). We first analysed the expression of HL-60 differentiation marker, CD11 b ${ }^{38}$. OR10G2 knockdown had no effect on CD11b expression level (Fig. 4B). Next, we performed cell counting and MTT assays whether cell proliferation changes caused by OR10G2 knockdown (Fig. 4C and D). Importantly, the growth of stable OR10G2 knockdown HL-60 cells was significantly lower than that of control HL-60 cells. Using fluorescence-activated cell sorting (FACS) analysis, we found that shOR10G2-1 and shOR10G2-2 cells exhibited decreased proportions of live cells (93.74\% to $77.25 \%$ and $90.52 \%$, respectively) and increased proportions of apoptotic cells $(4.49 \%$ to $19.50 \%$ and $6.72 \%)$ compared to control cells (Fig. 4E). These data suggest that OR10G2 affects the cell proliferation in HL-60 cells. To further analyse molecular mechanism by OR10G2 knockdown, we checked the expression level of several cell proliferation-related genes, ATF3, ATF5, C-Jun, HES5, PCK2 and WWP1 and anti-proliferation gene, Gadd45a, as a control in stable OR10G2 knockdown HL-60 cells ${ }^{39-45}$. As expected, these genes are significantly downregulated in stable OR10G2 knockdown HL-60 cells, while the mRNA level of Gadd45a was not changed (Fig. 4F). 
A

OR1N1

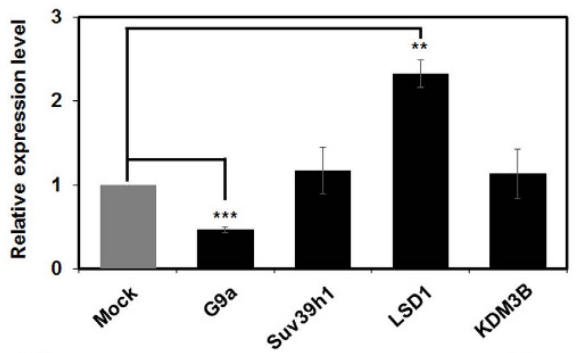

B

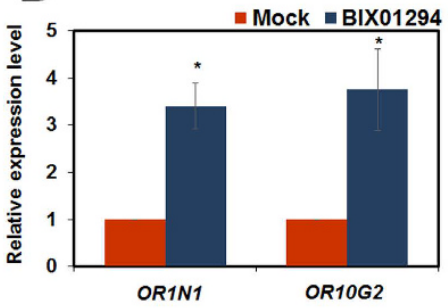

C

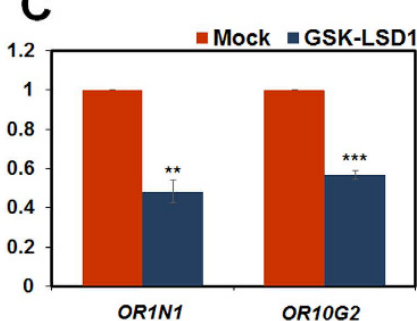

OR10G2

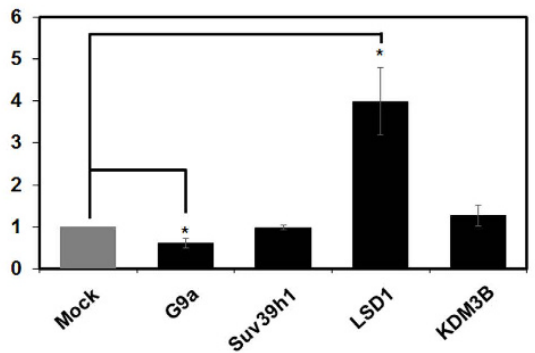

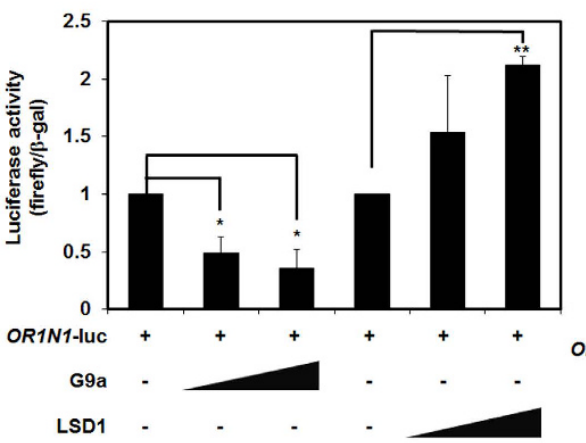

E

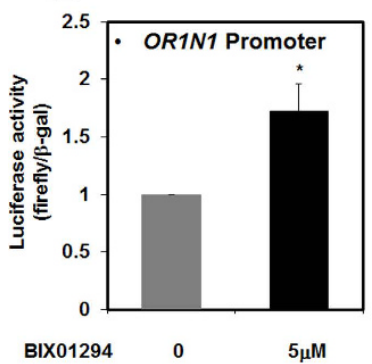

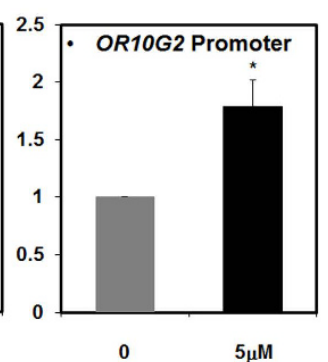

$\mathbf{F}$

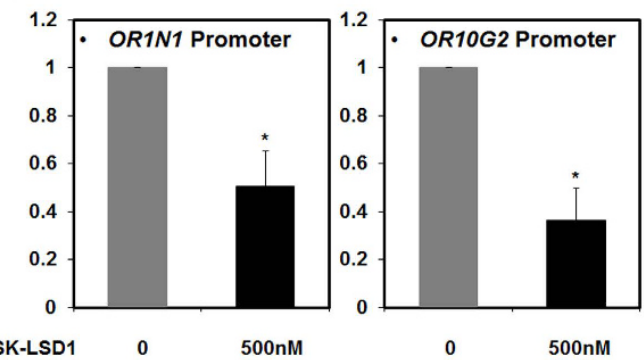

Figure 2. Expression of ORs is regulated by G9a and LSD1. (A) HCT116 and H1299 cells were transfected with pEGFP-G9a, pCMV-Suv39h1, pCMV-Flag-LSD1, and pCMV10-Flag-KDM3B. The mRNA levels of OR1N1 in HCT116 cells and OR10G2 in H1299 cells were analysed using qRT-PCR. (B) HL-60 cells were treated with the G9a inhibitor BIX01294 $(5 \mu \mathrm{M})$. After $48 \mathrm{~h}$, qRT-PCR was performed to compare the expression levels of each OR. (C) HL-60 cells were treated with the LSD1 specific inhibitor, GSK-LSD1 (500 nM). After 24h, qRT-PCR was performed to compare the expression levels of each ORs. (D) 293T cells were co-transfected with the pEGFP-G9a, pCMV-Flag-LSD1 and pGL4.12-OR1N1 or pGL4.12-OR10G2 promoters. Luciferase activities was measured $48 \mathrm{~h}$ after transfection. (E,F) $293 \mathrm{~T}$ cells were transfected with pGL4.12-OR1N1 or pGL4.12OR10G2 promoters. $24 \mathrm{~h}$ after transfection, BIX01294 $(5 \mu \mathrm{M})$ or GSK-LSD1 $(500 \mathrm{nM})$ were added for $24 \mathrm{~h}$, and luciferase activities were measured. Luciferase activities were normalised to that of $\beta$-galactosidase. (A-F) All results represent at least three independent experiments $( \pm$ SDs $) .{ }^{\star} P<0.05,{ }^{* *} P<0.01,{ }^{* *} P<0.001$.

These data show the regulatory roles of ORs in the proliferation of HL-60 cells, although ORs do not regulate directly HL-60 differentiation. Collectively, our results demonstrate that the regulation of OR transcription by 

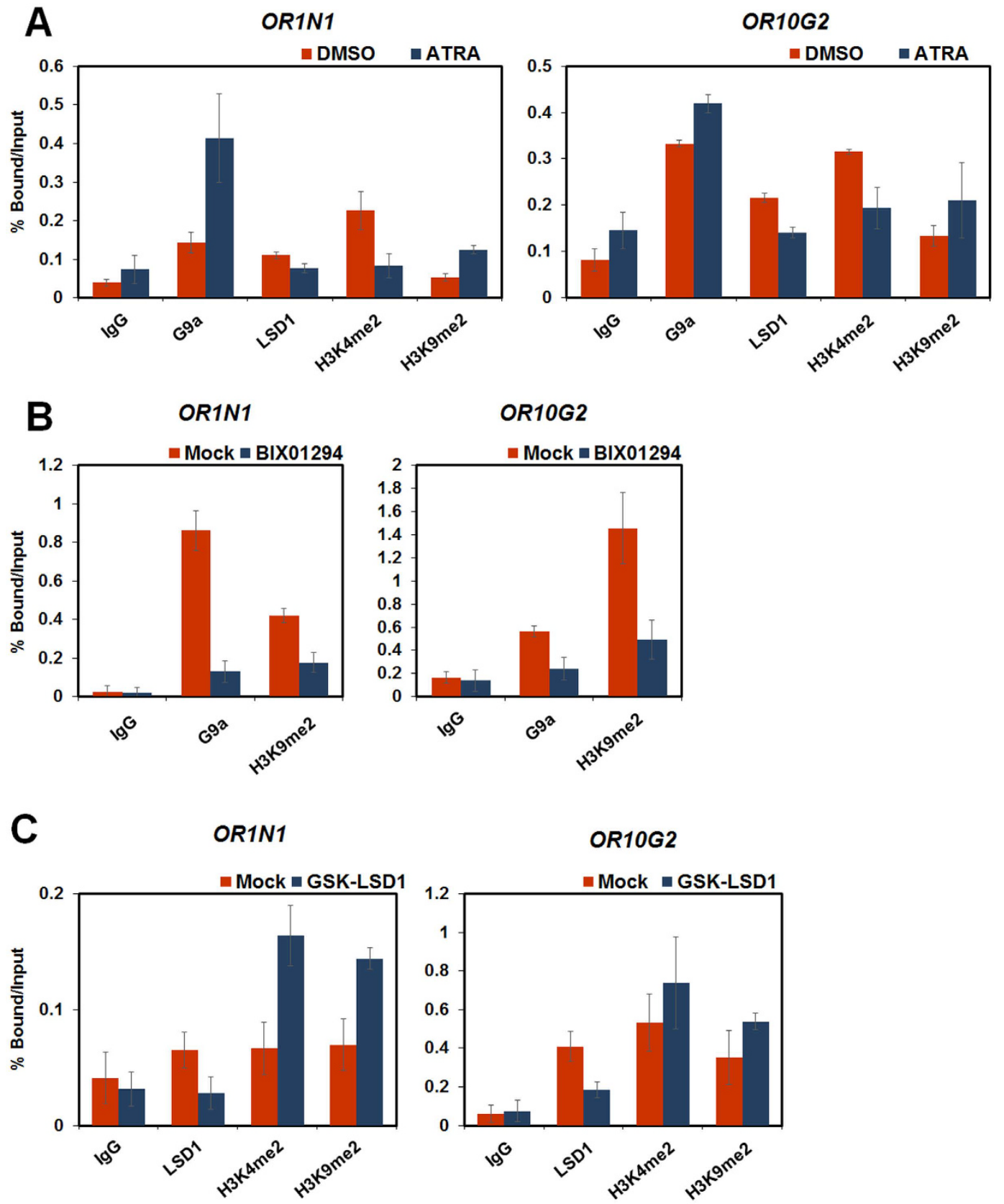

Figure 3. G9a and LSD1 regulate OR expression through the methylation and demethylation of H3K9. (A) ChIP analyses of the OR1N1 and OR10G2 promoters in ATRA-treated HL-60 cells were conducted using anti-G9a, anti-LSD1, anti-H3K4me2, anti-H3K9me2, and anti-IgG antibodies and were examined via qRTPCR analyses. (B,C) HL-60 cells were treated with BIX01294 (5 $\mu \mathrm{M})$ or GSK-LSD1 $(500 \mathrm{nM})$ for 48 or $24 \mathrm{~h}$, respectively. (B) ChIP analyses of the OR1N1 and OR10G2 promoters were performed using anti-G9a, antiH3K9me2, and anti-IgG antibodies and examined by qRT-PCR analyses. (C) Using anti-LSD1, anti-H3K4me2, anti-H3K9me2, and anti-IgG antibodies, ChIP analyses were performed. The results were analysed by qRTPCR. (A-C) These results are shown as mean \pm SDs. $(n=3)$.

G9a and LSD1 plays an important role in the proliferation of HL-60 cells, and that aberration of this regulation may contribute to leukaemogenesis.

\section{DISCUSSION}

Recent studies have revealed the functions of ectopically expressed ORs in various types of cells. ORs have functions in sperm chemotaxis, angiogenesis, maintenance of blood progenitor cells, and oncogenesis ${ }^{22,25,28,46}$. Moreover, ORs are also expressed in germinal cells, embryos, and developing heart and muscle, suggesting that they function during developmental stages ${ }^{47-52}$. ORs in non-olfactory tissues do not appear to be related to olfaction activity but rather perform their own different tissue-dependent functions $s^{53}$. 

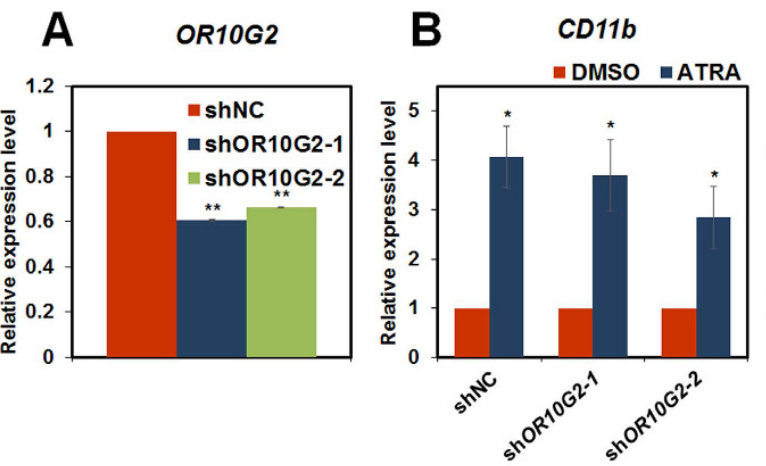

C

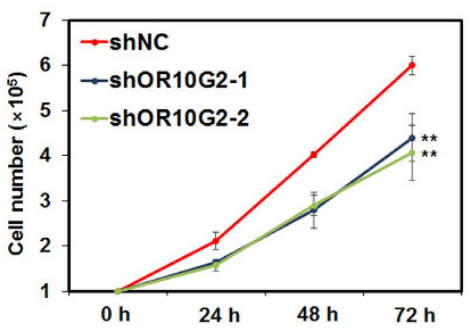

D

$F$
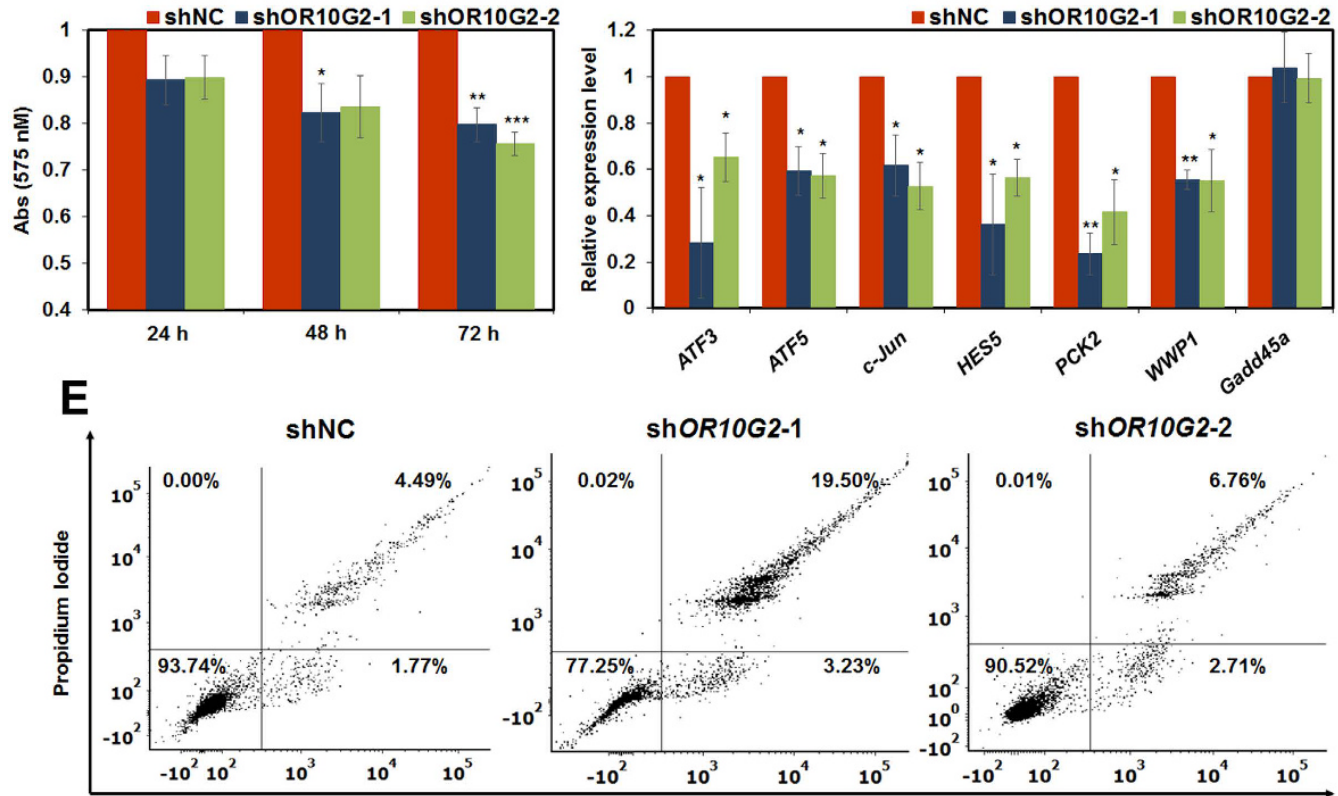

G

Annexin V-FITC

Undifferentiated

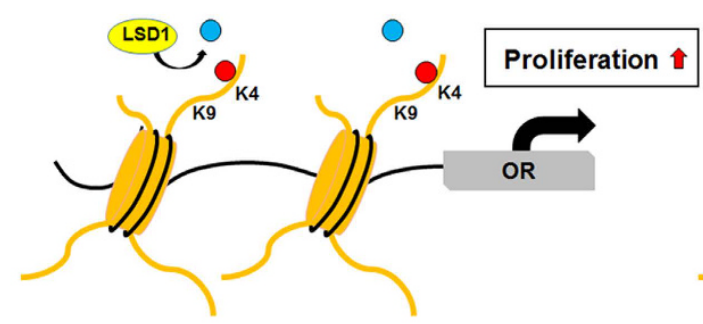

Differentiated

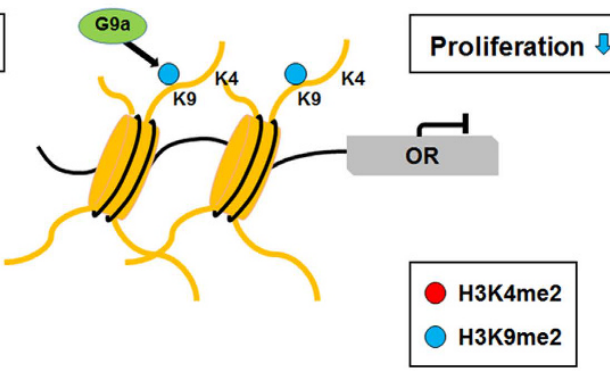

Figure 4. Down-regulation of OR10G2 decreases cell proliferation. (A) The mRNA level of OR10G2 in stable OR10G2 knockdown cells was measured by qRT-PCR analyses. (B) Stable OR10G2 knockdown HL-60 cells were treated with ATRA $(1 \mu \mathrm{M})$ or DMSO for $48 \mathrm{~h}$. qRT-PCR was performed to compare the expression levels of CD11b. (C) Cell counting assays were performed using stable OR10G2 knockdown HL-60 cells. (D) Cell proliferation was assessed through MTT assay in which stable OR10G2 knockdown HL-60 cells were used. (A-D) Results are expressed as means \pm SDs. $(\mathrm{n}=3)$. ${ }^{\star} P<0.05,{ }^{* \star} P<0.01,{ }^{* *} P<0.001$. (E) Apoptosis was measured in control and stable shOR10G2 HL-60 cell lines by PI and Annexin V-FTIC staining. Cells were stained with Annexin V-FITC and PI for $2 \mathrm{~h}$ and $30 \mathrm{~min}$, respectively, and analysed by FACS. (F) The mRNA levels of proliferation-related genes were measured by qRT-PCR. The results represent at least three independent experiments $( \pm \mathrm{SDs}) .{ }^{\star} P<0.05,{ }^{* *} P<0.01$. (G) A model of the regulation of ORs transcription by G9a and LSD1 during HL-60 differentiation is presented. 
Here, we demonstrated the epigenetic regulation of ORs and functions of OR10G2 during ATRA-mediated HL-60 differentiation. Transcription of ORs was activated by LSD1 and repressed by G9a in different cell types including HL-60 cells (Fig. 2 and Supplementary Figure S1 and S2). When HL-60 cells were differentiated via ATRA treatment, G9a was directly recruited to the OR promoters and the recruitment of LSD1 was reduced, catalysing the di-methylation of $\mathrm{H} 3 \mathrm{~K} 9$ and resulting in decreased OR expression (Fig. 3 and Supplementary Figure S3). Stable OR10G2 knockdown HL-60 cells exhibited decreased cell proliferation rate and increased apoptosis by reducing proliferation-related genes, suggesting that the function of OR10G2 in HL-60 cells may influence the survival of leukaemic cells (Fig. 4C-E). In summary, LSD1 activates the expression of ORs by demethylation of H3K9me2 in HL-60 cells. During ATRA-mediated HL-60 differentiation, G9a was recruited to the $O R$ promoters and repressed the expression of $O R s$ by mediating the methylation of $\mathrm{H} 3 \mathrm{~K} 9$. This in turn, caused the reduced cell proliferation of HL-60 cells (Fig. 4G).

In our previous ChIP-chip data, more than 30 ORs were regulated during HL-60 differentiation ${ }^{29}$. In this story, we analysed the epigenetic regulation of 4 OR genes, OR1N1, OR4F6, OR7A17 and OR10G2, and focused on the function of OR10G2 in HL-60 cells. However, there is a possibility that other ORs are involved in various cellular processes including proliferation via epigenetic regulations.

LSD1 has been known as both of $\mathrm{H} 3 \mathrm{~K} 4$ and $\mathrm{H} 3 \mathrm{~K} 9$ demethylase. We found that LSD1 activated $O R$ genes expression in HL-60 cells (Fig. 2 and Supplementary Figure S1 and S2). Interestingly, LSD1 inhibition resulted in the increase of the bivalent transcriptional histone markers, H3K4me2 and H3K9me2 (Fig. 3C and Supplementary Figure S3C). It is possible that the changes in $\mathrm{H} 3 \mathrm{~K} 4 \mathrm{me} 2$ level is a secondary effect of LSD1 inhibition. Also, LSD1 is known as demethylase of H3K4me1/2 and H3K9me2, not H3K4me3 $3^{10,11,37,54,55}$. Therefore, in this study, even though LSD1 demethylates $\mathrm{H} 3 \mathrm{~K} 4 \mathrm{me} 2, \mathrm{H} 3 \mathrm{~K} 4 \mathrm{me} 3$ might remain on $\mathrm{OR}$ gene promoter, and reduced $\mathrm{H} 3 \mathrm{~K} 9 \mathrm{me} 2$ level result in the activation of $O R$ expression. To further delineate the demethylase activities of LSD1 on OR promoters, further studies are needed.

Despite our current data demonstrating an oncogenic function for ORs, several studies have suggested that ORs may act as tumour suppressors ${ }^{24,56-58}$. The activation of OR2AT4 and OR51B5 in myelogenous leukaemia K562 cells, decreased proliferation and enhanced apoptosis and differentiation ${ }^{56,57}$. In addition, activation of OR51E1 in prostate cancer cells suppressed cell proliferation ${ }^{24,58}$. However, stimulation of ORs was also reported to promote cell invasiveness and metastasis ${ }^{59}$. Interestingly, OR51E2 has been reported to function as an oncogene and tumour suppressor in prostate cancer ${ }^{24,28}$. The activation of OR51E2 was reported to inhibit the proliferation of prostate cancer cells, while overexpression promoted the tumour development. These contradictions may be compatible with a hypothesis that a single OR can bind with multiple ligands, which have different potentials for downstream signal activation ${ }^{28}$. According to data from Olfaction DB, a single ligand can activate several $\mathrm{ORs}^{60}$. Even though ORs are receptors, the expression and activation by chemical agonists of ORs may lead to different physiological results. In cells, GPCRs can be activated by several molecules including hormones, peptides and other proteins ${ }^{61}$. Previous studies used chemical agonists to activate ORs, but it is possible that they also activate other ORs or GPCRs. As a result, the ORs in human leukaemic cells can be activated by molecules present in the human environment and may have their own pathways that differ from the activation by chemical ligands. It can be expected that differentially repressed ORs might lose their roles in cell proliferation. Since the ligand that activates OR10G2 has not yet been identified, the effect of OR10G2 activation in HL-60 cells remains unanswered. Nevertheless, OR10G2 is overexpressed in leukaemia cells and functions in cell proliferation in our study. Therefore, it is tempting to speculate that regulation of OR transcription can be an attractive new therapeutic target in leukaemogenesis.

\section{Methods}

Plasmid constructs. For the luciferase assay, genomic DNA was prepared and the OR1N1, OR4F6, OR7A17 and OR10G2 promoter region ( -1487 to $0,-1500$ to $+20,-1365$ to 0 and -1022 to 0 , respectively) was inserted into the pGL4.12-basic vector (Promega). The OR1N1, OR4F6, OR7A17 and OR10G2 promoter sequence were amplified from human genomic DNA using primer pairs (Supplementary Table S1). pEGFP-G9a, pCMV-FlagLSD1, pCMV-Suv39h1, and pCMV10-Flag-KDM3B were previously described ${ }^{6,8,62}$. Short hairpin RNAs (shRNAs) against G9a were previously described and against LSD1 and OR10G2 were designed using the siRNA sequence designer software (Clontech) ${ }^{6}$. A double-stranded oligonucleotide for shRNA plasmid construction was produced using primers from the $5^{\prime}$ to the $3^{\prime}$ end (Supplementary Table S1). These oligonucleotides were inserted into the AgeI/EcoRI site of the pLKO.1 TRC vector (Addgene).

Cell culture. HCT116, H1299 and HL-60 cells were grown in RPMI 1640, and G9a ${ }^{-1-}$ MEF and 293 T cells were cultured in Dulbecco's modified Eagle's medium supplemented with 10\% heat-inactivated FBS and $0.05 \%$ penicillin-streptomycin at $37^{\circ} \mathrm{C}$ in a $5 \% \mathrm{CO}_{2}$ atmosphere. For differentiation, HL-60 cells were seeded in $60 \mathrm{~mm}$ plate with $5 \times 10^{6}$ per $\mathrm{ml}$ and treated with $1 \mathrm{uM}$ ATRA or DMSO (Sigma). After $48 \mathrm{~h}$ incubation, the cells were harvested and used for each experiments. For inhibition of G9a and LSD1, HL-60 cells were seeded in $60 \mathrm{~mm}$ plate with $5 \times 10^{6}$ numbers and treated with the $5 \mu \mathrm{M}$ BIX01294 and $500 \mathrm{nM}$ GSK-LSD1, respectively. After $48 \mathrm{~h}$ and $24 \mathrm{~h}$ incubation respectively, cells were harvested and used in experiments.

Antibodies. Antibodies specific for $\beta$-Actin (sc-47778), LSD1 (sc-271720; Santa Cruz Biotechnology), G9a (07-551), H3K9me2 (07-441), H3K4me2 (07-030), and mouse IgG (12-371; Millipore) were purchased.

RNA interference. To produce virus particles, 293T cells were co-transfected with plasmids encoding VSV-G, NL-BH, and the shRNAs against G9a, LSD1 and OR10G2. Two days after transfection, the soups containing the viruses were collected and used to infect HL-60 cells in the presence of polybrene $(8 \mu \mathrm{g} / \mathrm{ml})$. 
Reverse Transcription PCR and qRT-PCR. Total RNA was isolated from cells using Tri-RNA Reagent (FAVORGEN). After cDNA synthesis, the cDNA was quantified and then subjected to analysis of mRNA expression. The PCR primers used are presented in Supplementary Table S1. Dissociation curves were examined after each PCR run to ensure amplification of a single product of the appropriate length. The mean threshold cycle $\left(\mathrm{C}_{\mathrm{T}}\right)$ and standard error values were calculated from individual $\mathrm{C}_{\mathrm{T}}$ values obtained from triplicate reactions per stage. The normalised mean $\mathrm{C}_{\mathrm{T}}$ value was estimated as $\Delta \mathrm{C}_{\mathrm{T}}$ by subtracting the mean $\mathrm{C}_{\mathrm{T}}$ of $\beta$-actin. The value $\Delta \Delta \mathrm{C}_{\mathrm{T}}$ was calculated as the difference between the control $\Delta \mathrm{C}_{\mathrm{T}}$ and the values obtained for each sample. The $\mathrm{n}$-fold change in gene expression, relative to an untreated control, was calculated as $2^{-\Delta \Delta C T}$.

Luciferase assay. For the luciferase assay, 293T cells were seeded in 48 -well plates and co-transfected with the indicated expression plasmid and the pGL4.12-OR1N1, pGL4.12-OR4F6, pGL4.12-OR7A17 and pGL4.12-OR10G2 reporter plasmid using polyethylenimine. After $48 \mathrm{~h}$, the cells were harvested and subjected to a luciferase assay (Promega). The level of $\beta$-galactosidase activities was used to normalise the reporter luciferase. Data are expressed as the means of four replicates from a single assay. All results shown are representative of at least three independent experiments.

ChIP and real-time PCR analysis. Cells were harvested and subsequently cross-linked with $1 \%$ formaldehyde. Briefly, $1 \%$ formaldehyde was added to the medium for $10 \mathrm{~min}$ at room temperature, followed by the addition of $125 \mathrm{mM}$ glycine for $5 \mathrm{~min}$ at room temperature. HL- 60 cells were centrifuged, and the resulting pellets were washed once with 1X PBS. The cell pellets were resuspended in SDS lysis buffer (1\% SDS, $10 \mathrm{mM}$ EDTA, $50 \mathrm{mM}$ Tris- $\mathrm{HCl}$ [pH 8.1]). Cells were then sonicated, and the lysates were subjected to immunoprecipitation using the indicated antibodies. The immunoprecipitates were eluted and reverse cross-linked, after which the DNA fragments were purified for PCR amplification. The DNA fragments were then purified and PCR amplified for quantification using each PCR primer pair (Supplementary Table S1). The thermal cycler conditions were as follows: 3 min of holding at $95^{\circ} \mathrm{C}$ followed by 45 cycles at $95^{\circ} \mathrm{C}$ for $10 \mathrm{~s}, 56^{\circ} \mathrm{C}$ for $10 \mathrm{~s}$, and $72{ }^{\circ} \mathrm{C}$ for $30 \mathrm{~s}$ (Bio-Rad). The mean threshold cycle $\left(\mathrm{C}_{\mathrm{T}}\right)$ and standard error values were calculated from individual $\mathrm{C}_{\mathrm{T}}$ values, obtained from duplicate reactions per stage.

MTT (3-(4,5-dimethylthiazol-2-yl)-2,5-diphenyltetrazolium bromide) Assay. shNC and shOR10G2 HL-60 cells were seeded in 48 -well plates with $5 \times 10^{5}$ per ml per each well. After 24,48 , and $72 \mathrm{~h}$, MTT was added to the cells (final concentration $0.5 \mathrm{mg} / \mathrm{ml}$ ), after which they were incubated further for $4 \mathrm{~h}$ at $37^{\circ} \mathrm{C}$. DMSO was added $(200 \mu \mathrm{l})$, and The OD was determined using a spectrophotometer at the wavelength of $575 \mathrm{~nm}$.

FACS analysis. To measure the effect of OR10G2 on apoptosis, HL-60 shOR10G2 stable cells were washed. Immediately before flow cytometric analysis, the cells were treated with RNase A $(20 \mathrm{mg} / \mathrm{ml})$ and stained with Annexin V-FITC (Biobud) for $2 \mathrm{~h}$ and propidium iodide (SIGMA) for $30 \mathrm{~min}$. HL-60 cells were then subjected to FACS analysis using a BD FACSAria ${ }^{\mathrm{TM}}$ II (BD bioscience), and the data were analysed using FCS Express 6 Plus (De Novo Software).

Statistical analysis. Data are expressed as means \pm SDs of three or more independent experiments. Statistical significance $(P<0.05)$ was calculated using functions in Microsoft Excel. Differences between groups were evaluated by one-way analysis of variance (ANOVA), followed by a student's t-test or Bonferroni test, as appropriate.

\section{References}

1. Sampath, S. C. et al. Methylation of a histone mimic within the histone methyltransferase G9a regulates protein complex assembly. Mol Cell 27, 596-608, doi: 10.1016/j.molcel.2007.06.026 (2007)

2. Tachibana, M. et al. G9a histone methyltransferase plays a dominant role in euchromatic histone H3 lysine 9 methylation and is essential for early embryogenesis. Genes Dev 16, 1779-1791, doi: 10.1101/gad.989402 (2002).

3. Tachibana, M. et al. Histone methyltransferases G9a and GLP form heteromeric complexes and are both crucial for methylation of euchromatin at H3-K9. Genes Dev 19, 815-826, doi: 10.1101/gad.1284005 (2005).

4. Dong, K. B. et al. DNA methylation in ES cells requires the lysine methyltransferase G9a but not its catalytic activity. EMBO J 27, 2691-2701, doi: 10.1038/emboj.2008.193 (2008).

5. Epsztejn-Litman, S. et al. De novo DNA methylation promoted by G9a prevents reprogramming of embryonically silenced genes. Nat Struct Mol Biol 15, 1176-1183, doi: 10.1038/nsmb.1476 (2008).

6. Kim, K. B. et al. H3K9 methyltransferase G9a negatively regulates UHRF1 transcription during leukemia cell differentiation. Nucleic Acids Res 43, 3509-3523, doi: 10.1093/nar/gkv183 (2015).

7. Dawson, M. A. et al. JAK2 phosphorylates histone H3Y41 and excludes HP1alpha from chromatin. Nature 461, 819-822, doi: 10.1038 /nature08448 (2009).

8. Son, H. J., Kim, J. Y., Hahn, Y. \& Seo, S. B. Negative regulation of JAK2 by H3K9 methyltransferase G9a in leukemia. Mol Cell Biol 32, 3681-3694, doi: 10.1128/MCB.00673-12 (2012).

9. Shi, Y. et al. Histone demethylation mediated by the nuclear amine oxidase homolog LSD1. Cell 119, 941-953, doi: 10.1016/j. cell.2004.12.012 (2004).

10. Metzger, E. et al. LSD1 demethylates repressive histone marks to promote androgen-receptor-dependent transcription. Nature 437, 436-439, doi: 10.1038/nature04020 (2005).

11. Lim, S. et al. Lysine-specific demethylase 1 (LSD1) is highly expressed in ER-negative breast cancers and a biomarker predicting aggressive biology. Carcinogenesis 31, 512-520, doi: 10.1093/carcin/bgp324 (2010).

12. Gaillard, I., Rouquier, S. \& Giorgi, D. Olfactory receptors. Cell Mol Life Sci 61, 456-469, doi: 10.1007/s00018-003-3273-7 (2004)

13. Durzynski, L. et al. Olfactory-like receptor cDNAs are present in human lingual cDNA libraries. Biochem Biophys Res Commun 333, 264-272, doi: 10.1016/j.bbrc.2005.05.085 (2005)

14. Glusman, G. et al. The olfactory receptor gene superfamily: data mining, classification, and nomenclature. Mammalian Genome 11, 1016-1023, doi: 10.1007/s003350010196 (2000). 
15. McClintock, T. S. Achieving singularity in mammalian odorant receptor gene choice. Chem Senses 35, 447-457, doi: 10.1093/ chemse/bjq041 (2010).

16. Lyons, D. B. et al. An epigenetic trap stabilizes singular olfactory receptor expression. Cell 154, 325-336, doi: 10.1016/j. cell.2013.06.039 (2013)

17. Lyons, D. B. et al. Heterochromatin-mediated gene silencing facilitates the diversification of olfactory neurons. Cell Rep 9, 884-892, doi: 10.1016/j.celrep.2014.10.001 (2014)

18. Magklara, A. et al. An epigenetic signature for monoallelic olfactory receptor expression. Cell 145, 555-570, doi: 10.1016/j. cell.2011.03.040 (2011).

19. Dalton, R. P., Lyons, D. B. \& Lomvardas, S. Co-opting the unfolded protein response to elicit olfactory receptor feedback. Cell 155, 321-332, doi: 10.1016/j.cell.2013.09.033 (2013).

20. Lomvardas, S. \& Maniatis, T. Histone and DNA Modifications as Regulators of Neuronal Development and Function. Cold Spring Harb Perspect Biol 8, doi: 10.1101/cshperspect.a024208 (2016).

21. Feingold, E. A., Penny, L. A., Nienhuis, A. W. \& Forget, B. G. An olfactory receptor gene is located in the extended human betaglobin gene cluster and is expressed in erythroid cells. Genomics 61, 15-23, doi: 10.1006/geno.1999.5935 (1999).

22. Spehr, M. et al. Identification of a testicular odorant receptor mediating human sperm chemotaxis. Science 299, 2054-2058, doi: 10.1126/science.1080376 (2003).

23. Otaki, J. M., Yamamoto, H. \& Firestein, S. Odorant receptor expression in the mouse cerebral cortex. J Neurobiol 58, 315-327, doi: 10.1002/neu.10272 (2004).

24. Neuhaus, E. M. et al. Activation of an olfactory receptor inhibits proliferation of prostate cancer cells. J Biol Chem 284, 16218-16225, doi: 10.1074/jbc.M109.012096 (2009).

25. Shim, J. et al. Olfactory control of blood progenitor maintenance. Cell 155, 1141-1153, doi: 10.1016/j.cell.2013.10.032 (2013).

26. Flegel, C. et al. Characterization of the Olfactory Receptors Expressed in Human Spermatozoa. Front Mol Biosci 2, 73, doi: 10.3389/ fmolb.2015.00073 (2015).

27. Kim, S. H. et al. Expression of human olfactory receptor $10 \mathrm{~J} 5$ in heart aorta, coronary artery, and endothelial cells and its functional role in angiogenesis. Biochem Biophys Res Commun, doi: 10.1016/j.bbrc.2015.03.046 (2015).

28. Rodriguez, M. et al. PSGR promotes prostatic intraepithelial neoplasia and prostate cancer xenograft growth through NF-kappaB. Oncogenesis 3, e114, doi: 10.1038/oncsis.2014.29 (2014).

29. Kim, J. Y. et al. KDM3B is the H3K9 demethylase involved in transcriptional activation of lmo2 in leukemia. Mol Cell Biol 32, 2917-2933, doi: 10.1128/MCB.00133-12 (2012).

30. Fazi, F. et al. Epigenetic silencing of the myelopoiesis regulator microRNA-223 by the AML1/ETO oncoprotein. Cancer Cell 12, 457-466, doi: 10.1016/j.ccr.2007.09.020 (2007).

31. Love, W. K., Berletch, J. B., Andrews, L. G. \& Tollefsbol, T. O. Epigenetic regulation of telomerase in retinoid-induced differentiation of human leukemia cells. Int J Oncol 32, 625-631 (2008).

32. Nowak, D., Stewart, D. \& Koeffler, H. P. Differentiation therapy of leukemia: 3 decades of development. Blood 113, 3655-3665, doi: 10.1182/blood-2009-01-198911 (2009).

33. Petrie, K., Zelent, A. \& Waxman, S. Differentiation therapy of acute myeloid leukemia: past, present and future. Curr Opin Hematol 16, 84-91, doi: 10.1097/MOH.0b013e3283257aee (2009).

34. Pospisil, V. et al. Epigenetic silencing of the oncogenic miR-17-92 cluster during PU.1-directed macrophage differentiation. EMBO J 30, 4450-4464, doi: 10.1038/emboj.2011.317 (2011).

35. Savickiene, J., Treigyte, G., Borutinskaite, V. V. \& Navakauskiene, R. Antileukemic activity of combined epigenetic agents, DNMT inhibitors zebularine and RG108 with HDAC inhibitors, against promyelocytic leukemia HL-60 cells. Cell Mol Biol Lett 17, 501-525, doi: 10.2478/s11658-012-0024-5 (2012).

36. Peters, A. H. et al. Partitioning and plasticity of repressive histone methylation states in mammalian chromatin. Mol Cell 12, $1577-1589$ (2003).

37. Greer, E. L. \& Shi, Y. Histone methylation: a dynamic mark in health, disease and inheritance. Nat Rev Genet 13, 343-357, doi: $10.1038 / \mathrm{nrg} 3173(2012)$.

38. Tang, H. et al. Regulation of CD11b transcription by decreasing PRC2 and increased acH4 level during ATRA-induced HL-60 differentiation. Acta Biochim Biophys Sin (Shanghai) 41, 588-593 (2009).

39. Bulavin, D. V., Kovalsky, O., Hollander, M. C. \& Fornace, A. J. Loss of Oncogenic H-ras-Induced Cell Cycle Arrest and p38 MitogenActivated Protein Kinase Activation by Disruption of Gadd45a. Molecular and Cellular Biology 23, 3859-3871, doi: 10.1128/ mcb.23.11.3859-3871.2003 (2003).

40. Hagiya, K., Yasunaga, J., Satou, Y., Ohshima, K. \& Matsuoka, M. ATF3, an HTLV-1 bZip factor binding protein, promotes proliferation of adult T-cell leukemia cells. Retrovirology 8, 19, doi: 10.1186/1742-4690-8-19 (2011).

41. Hui, L. et al. p38alpha suppresses normal and cancer cell proliferation by antagonizing the JNK-c-Jun pathway. Nat Genet 39, 741-749, doi: $10.1038 / \mathrm{ng} 2033$ (2007).

42. Ishihara, S. et al. Activating transcription factor 5 enhances radioresistance and malignancy in cancer cells. Oncotarget 6, 4602-4614, doi: 10.18632/oncotarget.2912 (2015).

43. Mendez-Lucas, A., Hyrossova, P., Novellasdemunt, L., Vinals, F. \& Perales, J. C. Mitochondrial phosphoenolpyruvate carboxykinase (PEPCK-M) is a pro-survival, endoplasmic reticulum (ER) stress response gene involved in tumor cell adaptation to nutrient availability. J Biol Chem 289, 22090-22102, doi: 10.1074/jbc.M114.566927 (2014).

44. Zhang, X. F. et al. Overexpression of WWP1 promotes tumorigenesis and predicts unfavorable prognosis in patients with hepatocellular carcinoma. Oncotarget 6, 40920-40933, doi: 10.18632/oncotarget.5712 (2015).

45. Zhu, G. et al. HES5 promotes cell proliferation and invasion through activation of STAT3 and predicts poor survival in hepatocellular carcinoma. Exp Mol Pathol 99, 474-484, doi: 10.1016/j.yexmp.2015.09.002 (2015).

46. Kim, S. H. et al. Expression of human olfactory receptor 10J5 in heart aorta, coronary artery, and endothelial cells and its functional role in angiogenesis. Biochem Biophys Res Commun 460, 404-408, doi: 10.1016/j.bbrc.2015.03.046 (2015).

47. Drutel, G. et al. Cloning of OL1, a putative olfactory receptor and its expression in the developing rat heart. Receptors Channels 3 , $33-40$ (1995)

48. Nef, S. \& Nef, P. Olfaction: transient expression of a putative odorant receptor in the avian notochord. Proc Natl Acad Sci USA 94, 4766-4771 (1997).

49. Dreyer, W. J. The area code hypothesis revisited: olfactory receptors and other related transmembrane receptors may function as the last digits in a cell surface code for assembling embryos. Proc Natl Acad Sci USA 95, 9072-9077 (1998).

50. Goto, T., Salpekar, A. \& Monk, M. Expression of a testis-specific member of the olfactory receptor gene family in human primordial germ cells. Mol Hum Reprod 7, 553-558 (2001).

51. Griffin, C. A., Kafadar, K. A. \& Pavlath, G. K. MOR23 promotes muscle regeneration and regulates cell adhesion and migration. Dev Cell 17, 649-661, doi: 10.1016/j.devcel.2009.09.004 (2009).

52. Baker, N. L., Miller, K. A., Newgreen, D. F. \& Farlie, P. G. Olfr603, an orphan olfactory receptor, is expressed in multiple specific embryonic tissues. Gene Expr Patterns 19, 30-35, doi: 10.1016/j.gep.2015.06.002 (2015).

53. Ferrer, I. et al. Olfactory Receptors in Non-Chemosensory Organs: The Nervous System in Health and Disease. Front Aging Neurosci 8, 163, doi: 10.3389/fnagi.2016.00163 (2016). 
54. Schulte, J. H. et al. Lysine-specific demethylase 1 is strongly expressed in poorly differentiated neuroblastoma: implications for therapy. Cancer Res 69, 2065-2071, doi: 10.1158/0008-5472.CAN-08-1735 (2009).

55. Shi, Y. J. et al. Regulation of LSD1 histone demethylase activity by its associated factors. Mol Cell 19, 857-864, doi: 10.1016/j. molcel.2005.08.027 (2005).

56. Manteniotis, S. et al. Functional characterization of the ectopically expressed olfactory receptor 2AT4 in human myelogenous leukemia. Cell Death Discov 2, 15070, doi: 10.1038/cddiscovery.2015.70 (2016).

57. Manteniotis, S. et al. Deorphanization and characterization of the ectopically expressed olfactory receptor OR51B5 in myelogenous leukemia cells. Cell Death Discov 2, 16010, doi: 10.1038/cddiscovery.2016.10 (2016).

58. Massberg, D. et al. The activation of OR51E1 causes growth suppression of human prostate cancer cells. Oncotarget, doi: 10.18632/ oncotarget.10197 (2016).

59. Sanz, G. et al. Promotion of cancer cell invasiveness and metastasis emergence caused by olfactory receptor stimulation. PLoS One 9, e85110, doi: 10.1371/journal.pone.0085110 (2014).

60. Modena, D., Trentini, M., Corsini, M., Bombaci, A. \& Giorgetti, A. OlfactionDB: A Database of Olfactory Receptors and Their Ligands. Advances in Life Sciences 1, 1-5, doi: 10.5923/j.als.20110101.01 (2012).

61. Parthier, C., Reedtz-Runge, S., Rudolph, R. \& Stubbs, M. T. Passing the baton in class B GPCRs: peptide hormone activation via helix induction? Trends Biochem Sci 34, 303-310, doi: 10.1016/j.tibs.2009.02.004 (2009).

62. Han, A. et al. Transcriptional repression of ANGPT1 by histone H3K9 demethylase KDM3B. BMB Reports 48, 401-406, doi: 10.5483/BMBRep.2015.48.7.188 (2015).

\section{Acknowledgements}

We thank Dr. Sung Hee Back of the Seoul National University for the pCMV-Flag-LSD1. This work was supported by the National Research Foundation of Korea (NRF) grant funded by the Ministry of Science, ICT \& Future Planning (NRF-2016R1A4A1008035) and the Environmental Health Center for Childhood Leukaemia and Cancer, Ministry of the Environment, Republic of Korea.

\section{Author Contributions}

H.S.J. designed the experiments and analysed the results. H.S.J., Y.C.C., J.Y.K., O.S.J. performed experiments. S.B.S. and H.S.J. wrote the manuscript. H. K. supervised the design of the experiments.

\section{Additional Information}

Supplementary information accompanies this paper at http://www.nature.com/srep

Competing Interests: The authors declare no competing financial interests.

How to cite this article: Jung, H. et al. Regulatory role of G9a and LSD1 in the Transcription of Olfactory Receptors during Leukaemia Cell Differentiation. Sci. Rep. 7, 46182; doi: 10.1038/srep46182 (2017).

Publisher's note: Springer Nature remains neutral with regard to jurisdictional claims in published maps and institutional affiliations.

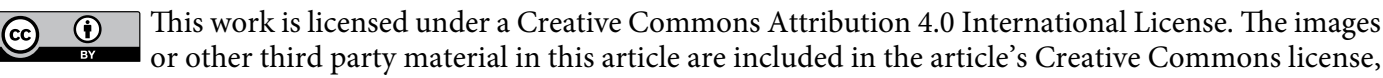
unless indicated otherwise in the credit line; if the material is not included under the Creative Commons license, users will need to obtain permission from the license holder to reproduce the material. To view a copy of this license, visit http://creativecommons.org/licenses/by/4.0/

(c) The Author(s) 2017 


\section{SCIENTIFIC REP}

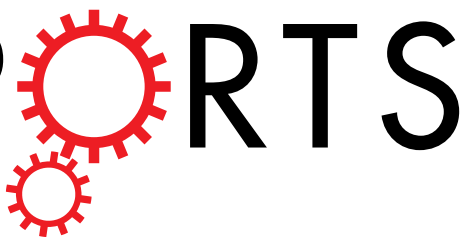

\section{OPEN}

\section{Author Correction: Regulatory role of G9a and LSD1 in the Transcription of Olfactory Receptors during Leukaemia Cell Differentiation}

\section{Hyeonsoo Jung ${ }^{1}$, Yun-Cheol Chae ${ }^{1}$, Ji-Young Kim ${ }^{1}$, Oh-Seok Jeong ${ }^{1}$, Hoon Kook ${ }^{2}$ \& Sang-} Beom Seo ${ }^{1}$

Correction to: Scientific Reports https://doi.org/10.1038/srep46182, published online 07 April 2017

This Article contains an error in the Abstract, where:

"Here, we identified that the H3K9me2 levels of several OR promoters decreased during differentiation in the HL-60, human myeloid leukaemia cell line, by all-trans-retinoic acid (ATRA)".

should read:

"Here, we identified that the $\mathrm{H} 3 \mathrm{~K} 9 \mathrm{me} 2$ levels of several OR promoters increased during differentiation in the HL-60, human myeloid leukaemia cell line, by all-trans-retinoic acid (ATRA)”.

(c) (i) Open Access This article is licensed under a Creative Commons Attribution 4.0 International License, which permits use, sharing, adaptation, distribution and reproduction in any medium or format, as long as you give appropriate credit to the original author(s) and the source, provide a link to the Creative Commons license, and indicate if changes were made. The images or other third party material in this article are included in the article's Creative Commons license, unless indicated otherwise in a credit line to the material. If material is not included in the article's Creative Commons license and your intended use is not permitted by statutory regulation or exceeds the permitted use, you will need to obtain permission directly from the copyright holder. To view a copy of this license, visit http://creativecommons.org/licenses/by/4.0/.

(C) The Author(s) 2018
${ }^{1}$ Department of Life Science, College of Natural Sciences, Chung-Ang University, Seoul, 156-756, Republic of Korea. ${ }^{2}$ Environmental Health Center for Childhood Leukaemia and Cancer, Department of Pediatrics, Chonnam National University Hwasun Hospital, Hwasun, 519-809, Republic of Korea. Correspondence and requests for materials should be addressed to S.-B.S. (email: sangbs@cau.ac.kr) 